\title{
Centrifuge Modeling for Mechanical Behavior of Liners in Damaged Host Pipes
}

\author{
Kohei Ono $^{1}$ - Yusuke Sonoda ${ }^{2}$ - Yutaka Sawada ${ }^{1}$. \\ Hoe I. Ling ${ }^{3}$ - Toshinori Kawabata ${ }^{1}$ (D)
}

\begin{abstract}
In Japan, a trenchless rehabilitation method has often been used for replacing aging irrigation pipes because of the economical reason. With the method, damaged host pipes are repaired with new pipes. Namely, the rehabilitated pipeline system comprises two pipes: a damaged host pipe and a liner. The mechanical behavior of liners is influenced by host pipes. In the present study, in order to reveal the mechanical behaviors, centrifuge model tests were carried out under various conditions including the damage levels of the host pipe, the positions of surcharge load, the ring stiffness of the liner, and the stiffness of the backfill. Test results indicate that the deflection of the liner increases with the damage level of the host pipe, and the influence of the host pipe on the liner is negligible when the host pipe reaches the ultimate damaged state. In addition, the strain concentration occurs at the crown of the inner due to the contact between the edge of the damaged host pipe and the liner. The strain concentration is reduced by $20 \%$ with the increase of the ring stiffness of the liner. It is also revealed that the strain concentration appears even if the stiffness of backfills increases.
\end{abstract}

Keywords Buried pipe $\cdot$ Trenchless method $\cdot$ Centrifuge model test $\cdot$ Strain $\cdot$ Deflection

Toshinori Kawabata

kawabata@kobe-u.ac.jp

1 Graduate School of Agricultural Science, Kobe University, 1-1 Rokkodai, Nada, Kobe, Hyogo 657-8501, Japan

2 Rural Development Bureau, Ministry of Agriculture, Forestry and Fisheries, 1-2-1 Kasumigaseki, Chiyoda, Tokyo 100-8950, Japan

3 Department of Civil Engineering and Engineering Mechanics, Columbia University, 500 west 120th street, New York 10027, USA 


\section{Introduction}

In Japan, the total length of irrigation and drainage channels is approximately $49,000 \mathrm{~km}$. Recently, the irrigation pipelines gradually lose its functionality because of deterioration and other factors, and the replacement or the improvement are required. Trenchless methods have been used for the pipe rehabilitation as the alternative to the conventional rehabilitation method because of the economical reason.

In the Japanese current design for irrigation pipelines [9], which has been developed on the basis of the work by Howard [5] and modified from the theory by Marston [8] and Spangler [12], the design of trenchless rehabilitation methods is not described at all.

As shown in Fig. 1, the concepts of the limit state stability for liners in damaged host pipes have been indicated by Moore [10]. Figure 1a shows the buckling of the liners due to external water pressure leaking through the cracks of the damaged host pipes. The limit stress was evaluated by Falter [3] with respect to the initial deformation and gap on the basis of structural analysis. In addition, EI-Sawy and Moore [2] investigated the stability of the liner by the finite element method (FEM).

In terms of the stability of liners against earth pressure, the restraint effect of damaged host pipes has been focused on. Takahashi et al. [14] investigated the deformation behavior of the liner at different damaged levels of the host pipe through a full-scale loading test, a series of centrifuge model tests, and FEM numerical analyses. As a result, it was revealed that the bending moment and the deformation of the liner were restrained since the damaged host pipe partially supported the external loads. In addition, Gumbel et al. [4] and Spasojevic et al. [13] carried out centrifuge model tests using four hinged pieces as damaged host pipes and observed the deformation behaviors of the liners under the several conditions (the host pipe deterioration, the void in the surrounding soil, and the traffic loading surcharge). The test results showed that the deformation of the liner increases with the progress of deterioration of the host pipes. On the contrary, the soil-host pipe-liner interaction was investigated by full-scale laboratory testing [6] and numerical analyses (Law and Moore [7]). From these studies, the local bending strain was observed in the liner at the crown and the invert, since the edges of the damaged host pipe contacted the liner pipe as shown in Fig. 1 b.

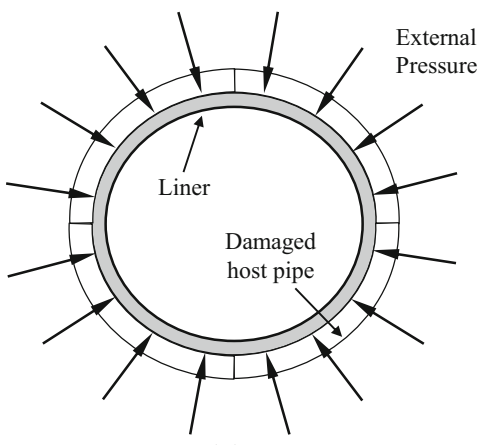

(a)

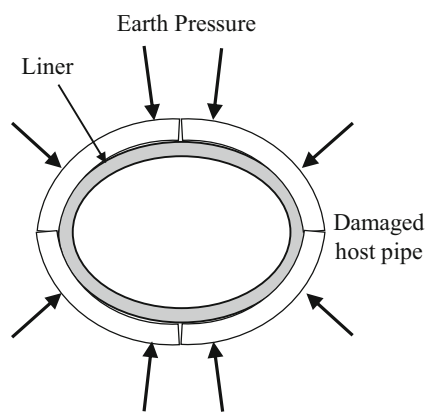

(b)

Fig. 1 Concepts of limit stats of stability for liners in damaged host pipes. a Buckling due to external fluid pressure acting through the damaged pipe. b Bending at crown and invert as a result of fractured pipe deformation (Moore 2008), modified by authors 
In the above previous studies about liners, the modeling of the damaged host pipe was limited. The quantitative evaluation of the effect of the damage level of the host pipe on the behavior of the liner had not been done. From this perspective, the authors conducted model experiments under the different damage levels of the host pipe (two cracks, four cracks, inclined four cracks, and eight cracks) [11]. From experimental results, the concentration of the strain was verified in the liner at the crown and the invert as mentioned by Law and Moore [6] even if the host pipe was fully deteriorated as eight cracks. Moreover, it was revealed that the concentration of the strain occurred in the liner at an angle of $45^{\circ}$ in the case of inclined four cracks. In the previous study, however, the model pipe was buried shallowly in 1-g field, and the restraint effect of the surrounding soil was relatively small. In the study by Allgood [1], it is known well that the mechanical behavior of a buried pipe depends on not only the ring stiffness of the pipe but also the soil stiffness. Thus, the effects of the density of the surrounding soil on the mechanical behavior of the liner should be investigated.

In the present study, in order to clarify the mechanical behaviors of liners affected by damaged host pipes subjected to the surcharge load, centrifuge model tests were conducted under several conditions (the damaged levels of the host pipe, the positions of the surcharge load, the ring stiffness of the liner, and the soil density). In order to model various damage levels of the host pipe, several aluminum segments $(2,4,8$, and 16) were used. In addition to the soil stiffness as mentioned above, the effects of the ring stiffness of the liner on the concentration of the strain were discussed. Moreover, the relationship between the varying positions of the surcharge load and the damage levels of the host pipe was investigated.

\section{Centrifuge Modeling}

\section{Model Pipe}

In order to simulate a damaged host pipe, aluminum segments were used as shown in Figs. 2 and 3. The model host pipes were divided into 2, 4, 8, and 16 segments assuming that the longitudinal cracks tend to occur at the crown, the invert, and the spring line, and especially during earthquake, the cracks appear at an angle of 45 or $135^{\circ}$ from the spring line [15]. The thickness of the segment was $10 \mathrm{~mm}$, and the outer diameter was $160 \mathrm{~mm}$ (the liner was fitted in the host pipe). The model of two cracks was assumed as the partial deterioration in which the host pipe had the ring stiffness against the external loads. The models of four and eight cracks were assumed as the full deterioration in which the host pipe had no bending stiffness to resist the external loads. Moreover, the model of 16 cracks represented further deteriorated state than the one of eight cracks. The initial clearance between the segments was $1 \mathrm{~mm}$.

As the model liner, two types of PVC pipes (\$140), which were different in thickness, were used as shown in Table 1. The ring stiffness of pipe B was approximately five times higher than that of pipe A.

The lengths of the model liner and the model host pipe were $100 \mathrm{~mm}$, and dummy pipes $(150 \mathrm{~mm})$ were connected to the both sides in order to reduce the influence of friction between the side wall of the model container and soils on the behavior of the model pipe. 
Fig. 2 Schematic diagrams of model pipes. a Liner only. $\mathbf{b}$ Two cracks. c Four cracks (cross). d Four cracks (inclined). e Eight cracks. f 16 cracks

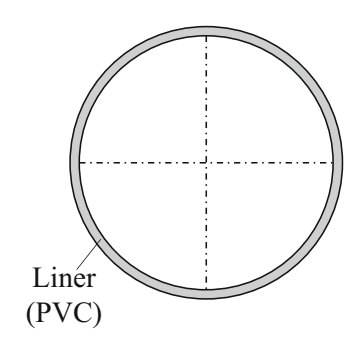

(a) Liner only

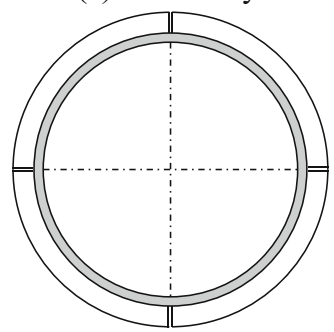

(c) Four cracks (cross)

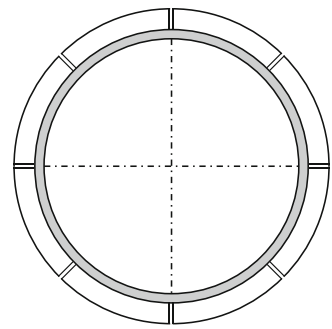

(e) Eight cracks

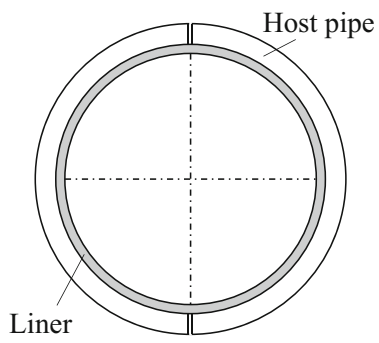

(b) Two cracks

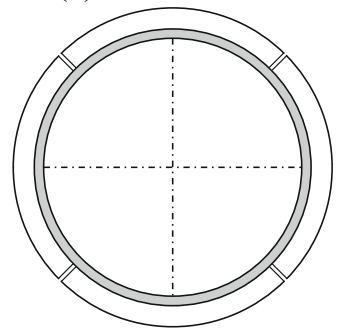

(d) Four cracks (inclined)

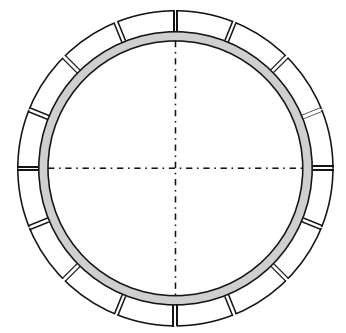

(f) 16 cracks

Fig. 3 Model pipe (eight cracks) 
Table 1 Properties of model pipes

\begin{tabular}{llllll}
\hline & Material & $\begin{array}{l}\text { Thickness } \\
t(\mathrm{~mm})\end{array}$ & $\begin{array}{l}\text { Diameter } \\
D(\mathrm{~mm})\end{array}$ & $\begin{array}{l}\text { Elastic modulus } \\
E\left(\mathrm{~N} / \mathrm{mm}^{2}\right)\end{array}$ & $\begin{array}{l}\text { Bending ring } \\
\text { stiffness } \\
E I / D^{3}\left(\mathrm{kN} / \mathrm{m}^{2}\right)\end{array}$ \\
\hline Liner (pipe A) & PVC & 4.1 & 140.0 & 3796 & 8.7 \\
Liner (pipe B) & & 7.0 & 140.0 & 3489 & 42.4 \\
Host pipe & Aluminum & 10.0 & 160.0 & - & - \\
\hline
\end{tabular}

\section{Instrumentation}

In order to evaluate the deformation behaviors of the liner accurately, 32 strain gauges were attached circumferentially to the inner surface of the PVC pipe, and vertical and horizontal deflection gauges were installed as shown in Fig. 4. The coefficients of deflection meters were calibrated under the centrifuge acceleration. Additionally, the front view of the model was monitored through the transparent front wall of the model container by using a CCD camera mounted on the swing platform of the centrifuge. Moreover, earth pressure cells were installed in the backfill as shown in Fig. 5.

\section{Model Preparation and Experimental Procedures}

As shown in Fig. 6, the model pipe was backfilled in the aluminum rigid model container with inner dimensions of $600 \times 400 \times 380 \mathrm{~mm}$. Two types of ground density were prepared $\left(D_{r} 20\right.$ and $\left.70 \%\right)$. Nevada sand was used as the backfill material, and the properties and the grain size distribution are shown in Table 2 and Fig. 7, respectively.

After the completion of backfill, the model was mounted on the platform. All tests were carried out at $21.4 \mathrm{~g}$ using the geotechnical centrifuge facilities at Columbia University with a radius of $2.75 \mathrm{~m}$ and a capacity of $200 \mathrm{~g}$ as shown in Fig. 8. The model liner at $21.4 \mathrm{~g}$ simulates a prototype liner having an outer diameter of $3000 \mathrm{~mm}$.

After the centrifuge acceleration reached $21.4 \mathrm{~g}$, the distributed load of $140 \mathrm{~mm}$ was applied to the ground surface up to $200 \mathrm{kN} / \mathrm{m}^{2}$ as the vertical surcharge (traffic loads,

Fig. 4 Configuration of sensors

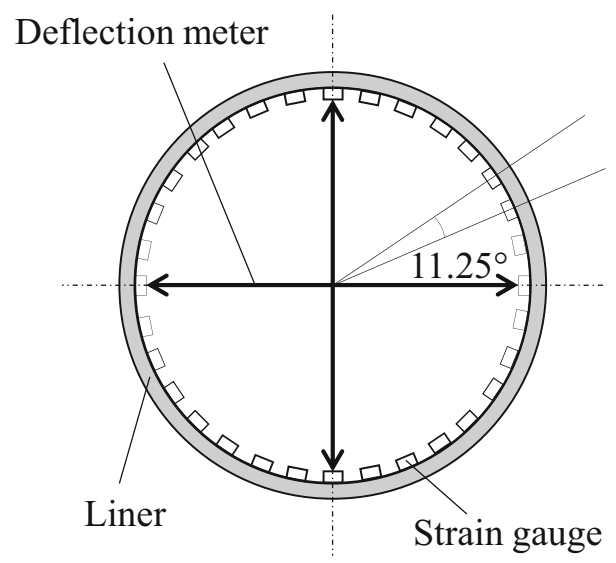




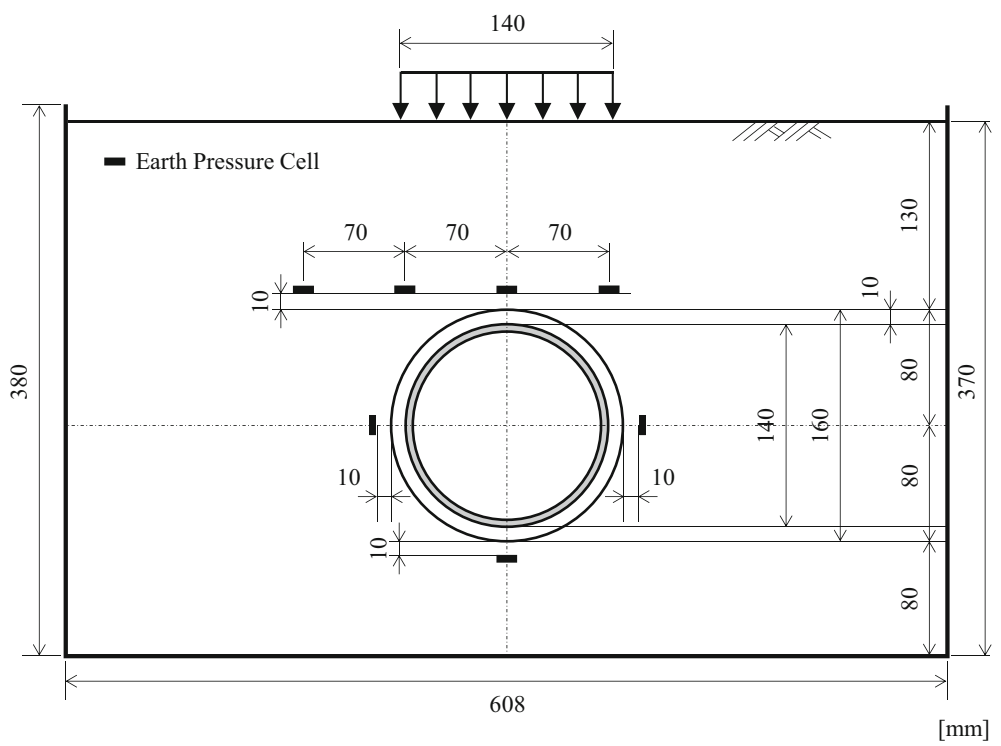

Fig. 5 Cross section of model test

snow loads, and building weight over the buried pipe), using an air bag controlled by a regulator outside the centrifuge facility. The loading width is equivalent to the diameter of the model pipe, and the loading positions were set just above the pipe (hereinafter called centric loading) and $140 \mathrm{~mm}$ away from the center (hereinafter called eccentric loading).

\section{Test Conditions}

Table 3 shows the test conditions. Tests were divided into four series according to the experimental conditions of the loading position (centric and eccentric), the model liner (pipe A or pipe B), and the ground density (loose or dense). In each test series, liner only and four or five cases with different damage levels of the host pipe were conducted.

Fig. 6 Model pipe during backfilling

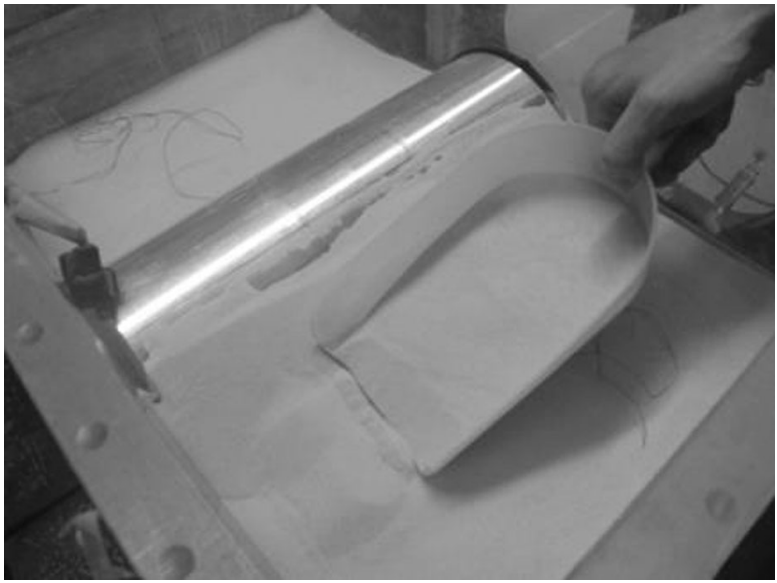


Table 2 Properties of Nevada sand

\begin{tabular}{ll}
\hline Density of soil particle, $\rho_{s}\left[\mathrm{~g} / \mathrm{cm}^{3}\right]$ & 2.65 \\
Maximum dry density, $\rho_{\max }\left[\mathrm{g} / \mathrm{cm}^{3}\right]$ & 1.40 \\
Minimum dry density, $\rho_{\min }\left[\mathrm{g} / \mathrm{cm}^{3}\right]$ & 1.74 \\
Uniformity coefficient, $U_{c}$ & 1.57 \\
Coefficient of curvature, $U_{c}$, & 0.87 \\
Cohesion, $c$ & 0 \\
\hline
\end{tabular}

\section{Results and Discussion}

\section{Inner Circumferential Strain Distributions of Liners}

Figure 9 shows the inner circumferential strain distributions of the model liners at the centric load of $200 \mathrm{kN} / \mathrm{m}^{2}$ in series 1 . Note that the positive value means the tensile strain. In S1-2, the strains are almost zero. This result indicates that the host pipe having two cracks keeps enough bending stiffness to resist against the external loads. On the other hand, in S1-4c, S1-4i, and S1-8, the concentrated strains occur at the points of cracks. Especially in S1-8, the strain is about $8000 \mu$ at the crown. These behaviors are similar to those observed in the previous study [11]. It is assumed that the concentrated force acts on the points of cracks due to the contact with the edge of the damaged pipe. In $\mathrm{S} 1-16$, the distribution is almost the same as S1-0. When the host pipe reaches the serious damaged state, the influence of the host pipe on the liner is negligible.

Figure 10 shows the inner circumferential strain distributions of the model liners at the eccentric load of $200 \mathrm{kN} / \mathrm{m}^{2}$ in series 2. The applied load is dispersed and transferred to the pipe from a diagonal direction. In comparison with series 1 , the values are considerably small because of the dispersion of loads. In S2-0, S2-4i, S2-8, and S2-16, the large strains occur in a direction of $315^{\circ}$. Especially, in S2-8, the large strain locally occurs at the direction. On the other hand, in S2-4c, the positive strains occur in a direction of 0 and $281.25^{\circ}$. There is no crack in a direction of $315^{\circ}$ in S2-4c. Namely, the deformation behavior of the liner is governed by the relationships between the positions of cracks in the damaged host pipe and the direction of the external load.

Figure 11 shows the inner circumferential strain distributions in pipe A (S1-0 and S1-8) and pipe B (S3-0 and S3-8) when both vertical deflections are at the same degree. From Fig. 11a, it can be seen that the local strains at the crown are different between

Fig. 7 Grain size distribution

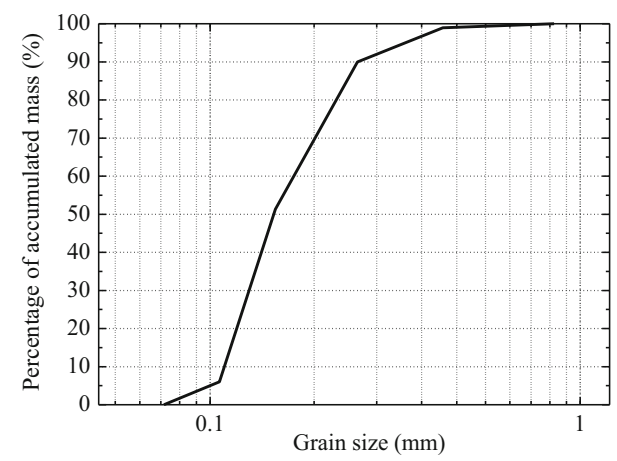


Fig. 8 Centrifuge facility in centrifuge center (Columbia University)

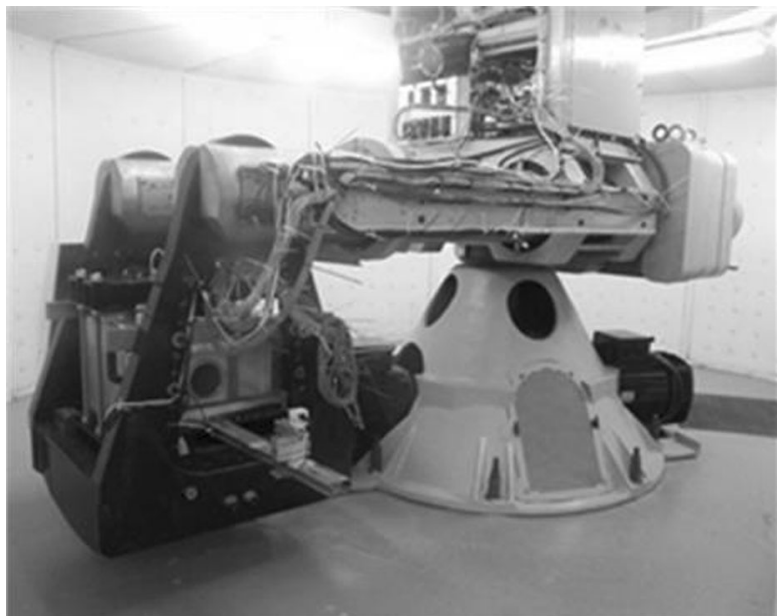

both pipes. In general, if the deflections are at the same degree, the strain at the surface increases according to the thickness. However, the strain at the crown in pipe B is

Table 3 Experimental cases

\begin{tabular}{|c|c|c|c|c|c|}
\hline Series & Case & State of host pipe & Liner & Loading position & $\begin{array}{l}\text { Ground } \\
\text { condition }\end{array}$ \\
\hline Series 1 & $\begin{array}{l}\text { S1-0 } \\
\text { S1-2 } \\
\text { S1-4c } \\
\text { S1-4i } \\
\text { S1-8 } \\
\text { S1-16 }\end{array}$ & $\begin{array}{l}\text { None (liner only) } \\
2 \text { cracks } \\
4 \text { cracks (cross) } \\
4 \text { cracks (inclined) } \\
8 \text { cracks } \\
16 \text { cracks }\end{array}$ & Pipe A & $\begin{array}{l}\text { Centric loading } \\
\text { (center of sand box) }\end{array}$ & $\begin{array}{l}\text { Loose } \\
\operatorname{Dr} 20 \%\end{array}$ \\
\hline Series 2 & $\begin{array}{l}\text { S2-0 } \\
\text { S2-2 } \\
\text { S2-4c } \\
\text { S2-4i } \\
\text { S2-8 } \\
\text { S2-16 }\end{array}$ & $\begin{array}{l}\text { None (liner only) } \\
2 \text { cracks } \\
4 \text { cracks (cross) } \\
4 \text { cracks (inclined) } \\
8 \text { cracks } \\
16 \text { cracks }\end{array}$ & Pipe A & $\begin{array}{l}\text { Eccentric loading } \\
\text { (140 mm from center) }\end{array}$ & $\begin{array}{l}\text { Loose } \\
\operatorname{Dr} 20 \%\end{array}$ \\
\hline Series 3 & $\begin{array}{l}\text { S3-0 } \\
\text { S3-2 } \\
\text { S3-4c } \\
\text { S3-8 } \\
\text { S3-16 }\end{array}$ & $\begin{array}{l}\text { None (liner only) } \\
2 \text { cracks } \\
4 \text { cracks (cross) } \\
8 \text { cracks } \\
16 \text { cracks }\end{array}$ & Pipe B & $\begin{array}{l}\text { Centric loading } \\
\text { (center of sand box) }\end{array}$ & $\begin{array}{l}\text { Loose } \\
\operatorname{Dr} 20 \%\end{array}$ \\
\hline Series 4 & $\begin{array}{l}\text { S4-0 } \\
\text { S4-4c } \\
\text { S4-4i } \\
\text { S4-8 } \\
\text { S4-16 }\end{array}$ & $\begin{array}{l}\text { None (liner only) } \\
4 \text { cracks (cross) } \\
4 \text { cracks (inclined) } \\
8 \text { cracks } \\
16 \text { cracks }\end{array}$ & Pipe A & $\begin{array}{l}\text { Centric loading } \\
\text { (center of sand box) }\end{array}$ & $\begin{array}{l}\text { Dense } \\
\operatorname{Dr} 70 \%\end{array}$ \\
\hline
\end{tabular}




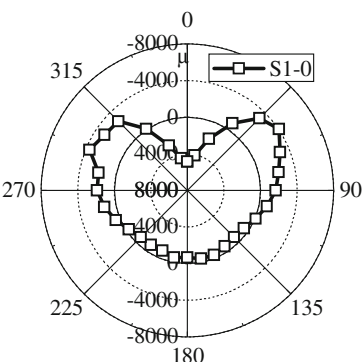

(a) Liner only

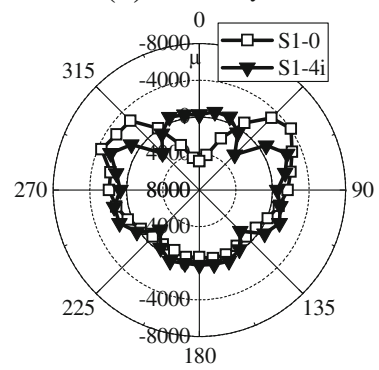

(d) Four cracks (inclined)

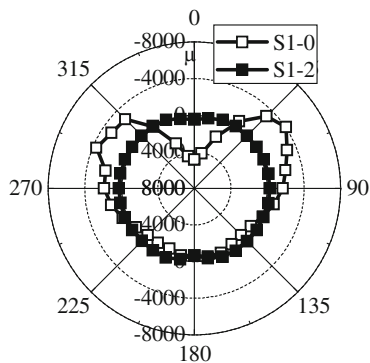

(b) Two cracks

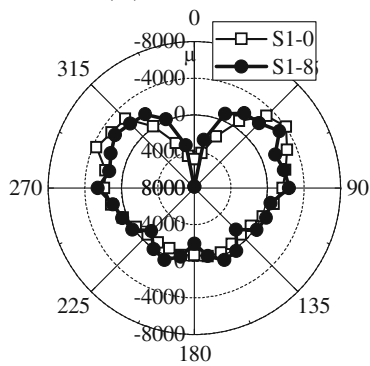

(e) Eight cracks

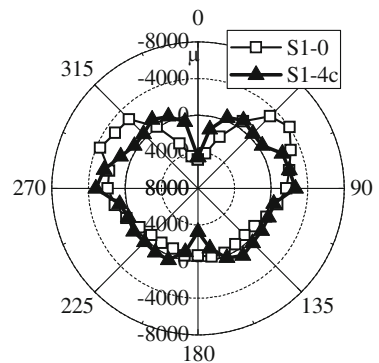

(c) Four cracks (cross)

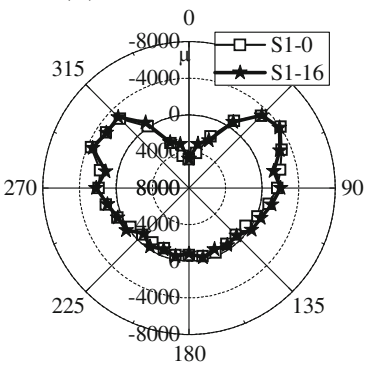

(f) 16 cracks

Fig. 9 Inner circumferential strain distributions (series 1). a Liner only. b Two cracks. c Four cracks (cross). d Four cracks (inclined). e Eight cracks. f 16 cracks

smaller than that in pipe A. From Fig. 11a, it can be seen that the strains in the upper half are larger than those in the lower half in pipe A. In contrast, the deformation in pipe B seems to be relatively uniform. In other words, the strain at the crown is absorbed

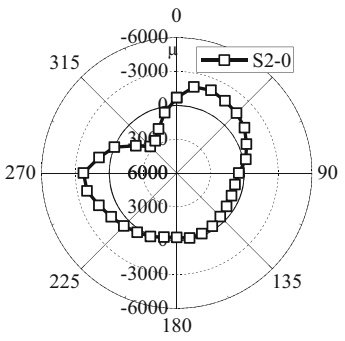

(a) Liner only

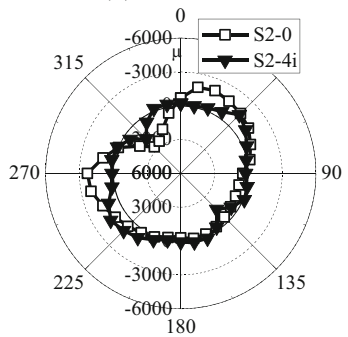

(d) Four cracks (inclined)

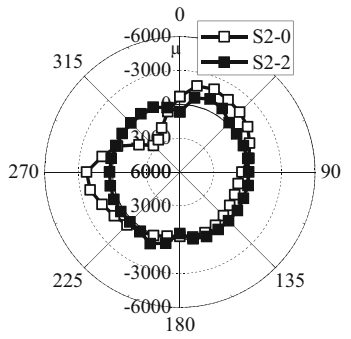

(b) Two cracks

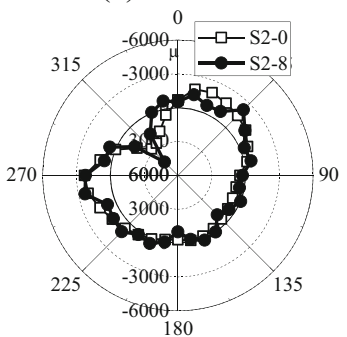

(e) Eight cracks

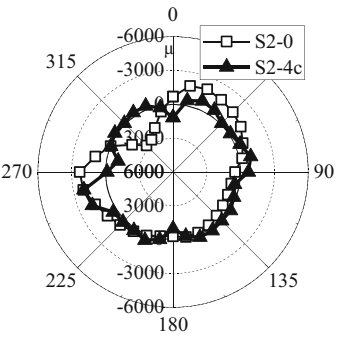

(c) Four cracks (cross)

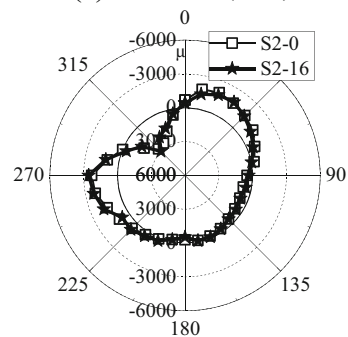

(f) 16 cracks

Fig. 10 Inner circumferential strain distributions (series 2). a Liner only. b Two cracks. c Four cracks (cross). d Four cracks (inclined). e Eight cracks. f 16 cracks 
Fig. 11 Inner circumferential strain distributions (pipe $\mathrm{A}$ and pipe $\mathrm{B})$. a $\mathrm{S} 1-0$ and $\mathrm{S} 3-0$. b $\mathrm{S} 1-8$ and S3-8

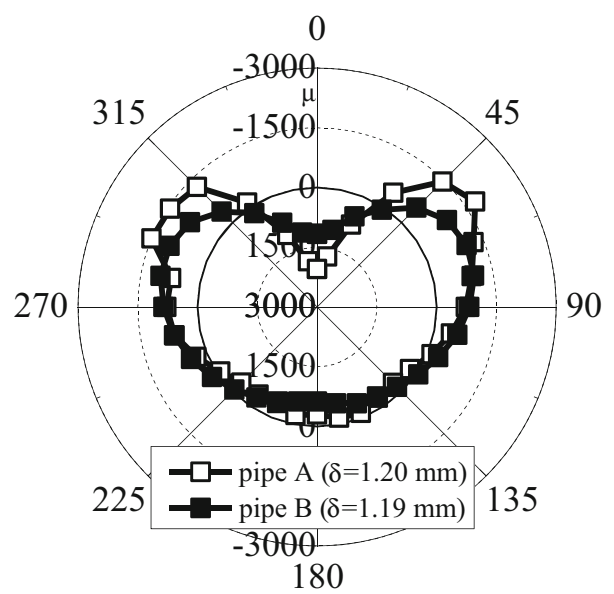

(a) S1-0 and S3-0

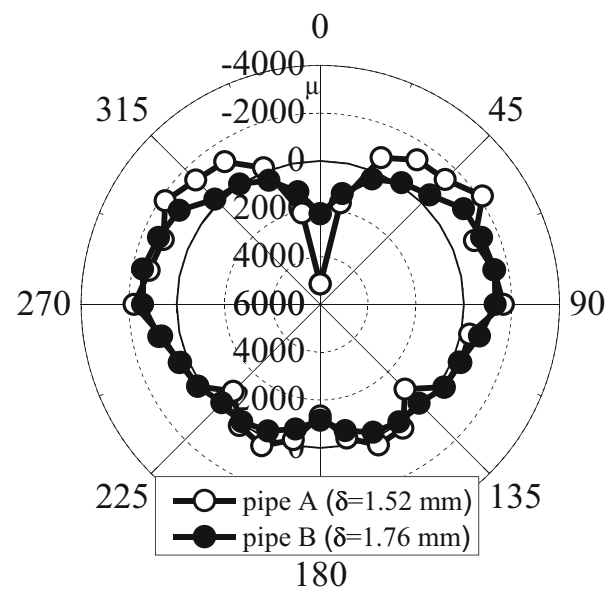

(b) S1-8 and S3-8

into the deformation at the other part. In the same way, from Fig. 11b, although the concentrated strain can be seen at the crown in both cases, the degree of the strain localizing in pipe $\mathrm{B}$ is smaller than that in pipe A. The results imply that a ring stiffness of pipe should be considered in the design as the important factor in terms of the risk of concentrated strain.

As mentioned before, deformation behaviors of buried pipes depend on not only the ring stiffness but also the soil stiffness. It is well known that deformations decrease with the increase of the soil stiffness. Figure 12 shows the inner circumferential strain distributions in S4-0 and S4-8 (series 4, dense ground). In S4-0, the inner circumferential strains are remarkably small due to the high soil density. In comparison with S1-0 in Fig. 9a, the strain at the crown of the pipe declines by about $85 \%$ at the centric load of $200 \mathrm{kN} / \mathrm{m}^{2}$. In addition, the inner strains of the liner are small also in S4-8, and the soil stiffness around the pipe affects the deformation behavior of the liner. At the crown of the pipe, however, the concentrated strain still occurs even if the soil stiffness of the backfill is high. 
Fig. 12 Inner circumferential strain distributions (S4-0 and S4-8)

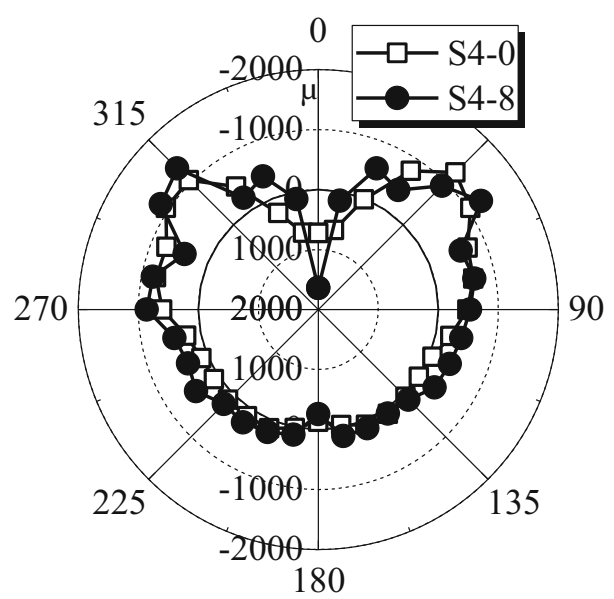

\section{Deflections of Liners (Series 1 and 2)}

Figure 13 shows changes in the vertical and the horizontal deflections with the increase of the vertical surcharge in series 1. It is clear that the vertical and the horizontal deflections are roughly the same. In S1-2, the vertical and the horizontal deflections are the smallest in all cases, and they are approximately $10 \%$ of S1-0 (liner only). The deflections of S1-4i are also significantly small, and they are approximately $20 \%$ of S1-0. As shown in Fig. 9d, it is assumed that the host pipe has enough bending stiffness at the crown, the invert, and the spring line of the liner. In S1-4c and S1-8, the deflections are also smaller than that in S1-0. In comparison between S1-4c and S18 , although the horizontal deflections can be regarded as the same degree, it is slightly larger in S1-8 in terms of the vertical deflections. As mentioned above, this is attributed

Fig. 13 Relationships between vertical surcharge load and deflection ratios (series 1)

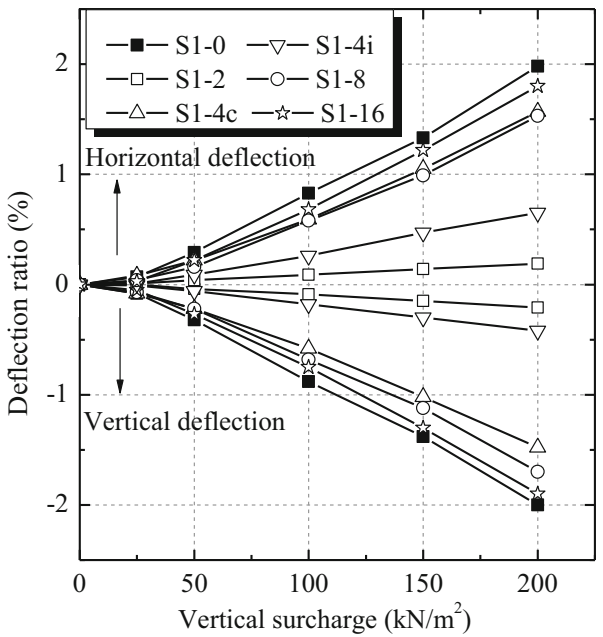


Fig. 14 Relationships between vertical surcharge load and deflection ratios (series 2)

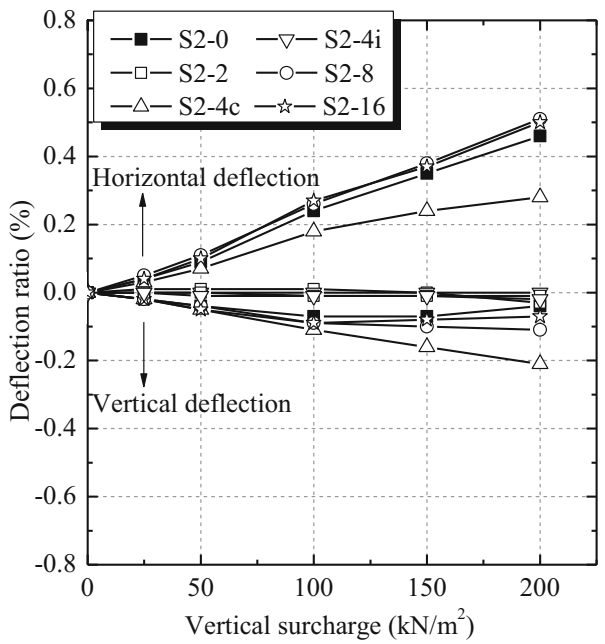

to the concentration of strain at the crown. In S1-16, the deflections are close to that in S1-0. From these results, it is revealed that the effect of the host pipe on the restraint of the deflection of the liner disappears at the ultimate damaged state of the host pipe.

Figure 14 shows changes in the vertical and the horizontal deflections with the increase of the vertical surcharge in series 2. In S2-0, S2-8, and S2-16, it can be seen that there are differences between the vertical and the horizontal deflections. It seems that the horizontal deflection is larger than vertical deflection. The difference is attributed to the fact that the pipe deformed in an oblique direction due to eccentric load as shown in Fig. 10. On the other hand, in S2-4c, it can be seen that the differences between the vertical and the horizontal deflections is relatively small. It means that the concentrated force occurs at the crown and the spring line of the liner due to the contact between the liner and the host pipe even if the applied load is transferred to the host pipe from a diagonal direction.

\section{Influence of Damage Level of Host Pipe on Mechanical Behavior of Liner}

Table 4 shows the index values of the deflections. The index values were determined as the vertical deflections normalized with respect to that of the case with liner only. Note that the values at the load of $200 \mathrm{kN} / \mathrm{m}^{2}$ are listed up. In all series, the index values are

Table 4 Index values of deflections

\begin{tabular}{lllllll}
\hline Series & $\begin{array}{l}\text { Liner } \\
\text { only }\end{array}$ & 2 cracks & 4 cross & $\begin{array}{l}4 \\
\text { inclined }\end{array}$ & $\begin{array}{l}8 \\
\text { cracks }\end{array}$ & $\begin{array}{l}16 \\
\text { cracks }\end{array}$ \\
\hline 1 & 1 & 0.10 & 0.74 & 0.21 & 0.85 & 0.95 \\
2 & 1 & - & - & - & - & - \\
3 & 1 & 0.19 & 0.82 & - & 0.92 & 1.07 \\
4 & 1 & - & 0.64 & 0.50 & 1.07 & 0.96 \\
\hline
\end{tabular}


Table 5 Index values of maximum strain

\begin{tabular}{lllllll}
\hline Series & $\begin{array}{l}\text { Liner } \\
\text { only }\end{array}$ & $\begin{array}{l}2 \\
\text { cracks }\end{array}$ & 4 cross & $\begin{array}{l}4 \\
\text { inclined }\end{array}$ & $\begin{array}{l}8 \\
\text { cracks }\end{array}$ & $\begin{array}{l}16 \\
\text { cracks }\end{array}$ \\
\hline 1 & 1 & 0.14 & 0.94 & 0.52 & 1.63 & 0.99 \\
2 & 1 & 0.25 & 0.44 & 0.62 & 1.61 & 1.11 \\
3 & 1 & 0.26 & 1.12 & - & 1.31 & 1.07 \\
4 & 1 & - & 0.50 & 1.37 & 2.27 & 1.20 \\
\hline
\end{tabular}

less than 1.1. It implies that the damaged host pipe does not increase the deflection of the liner. However, the values are significantly different between the damage levels of the host pipe. In cases of two cracks, the values are less than 0.2 , since the host pipe keeps enough bending stiffness to resist the external load. In cases of four cross cracks, the values are from 0.6 to 0.9 . Although there are cracks at the crown, the invert, and the spring line, the host pipe supported partially the external load. In cases of eight cracks, the values are from 0.8 to 1.1 . The restraint effect of the host pipe is very slight. In cases of 16 cracks, the values are around 1.0. It means that the restraint effect is not expected.

In the Japanese current design for flexible pipelines [9], in terms of the structural safety in the cross section of pipeline, the stress is checked assuming the earth pressure distributions based on the theory by Marston [8] and Spangler [12]. On the other hand, leakage occurs at pipe joints, cracks of paint are induced, and area of flow is not ensured if deflections remarkably become large. Thus, the allowable deflection ratio is determined as $5 \%$. In general design, a required thickness of pipe is calculated on the basis of the allowable deflection ratio. However, in liners, this design criterion should not be applied because the risk of concentrated strain is not appropriately considered.

Table 5 shows the index values of the maximum strains. The index values are determined as the maximum strains normalized with respect to that of the case with liner only. In cases of 16 cracks, the ratios are around 1.0, and they are corresponding to the ratio of deflection as shown in Table 4. On the other hand, in cases of eight cracks for all series, the ratio is larger than 1.3. As mentioned above, this is attributed to the concentration of strain at the crown of the liner. When the ring stiffness of liner increases by five times, the strain localizing at the crown is reduced by $20 \%$. However, even if the soil stiffness increases, the index value is not reduced.

Fig. 15 Relationships between vertical earth pressures and maximum tensile strains (S1-0 and S1-8)

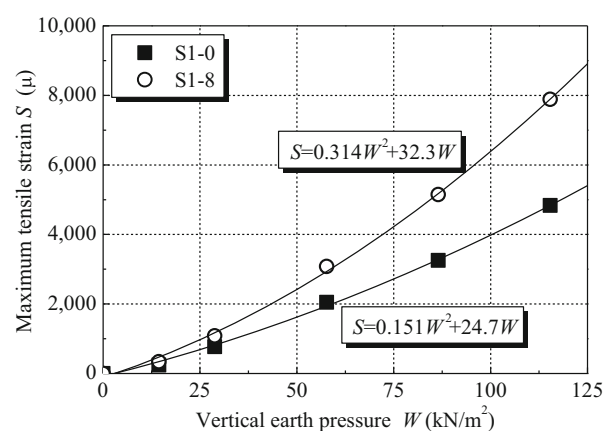


Fig. 16 Relationships between deflection ratios and maximum tensile strains (series 1)

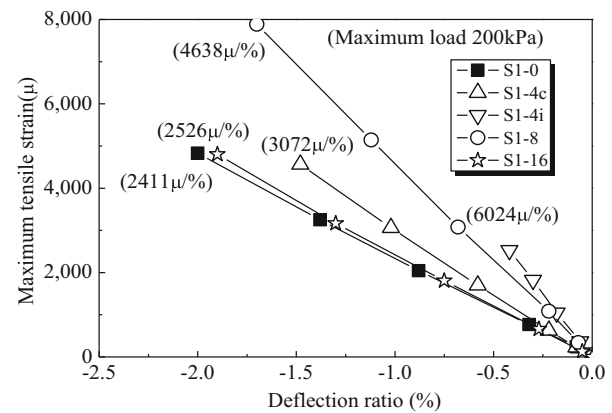

Figure 15 shows the relationships between the vertical earth pressure and the maximum tensile strain in S1-0 and S1-8. In this figure, the vertical earth pressure acting on the pipe was calculated from the applied surcharge load on the ground surface using Boussinesq solution. From this figure, it is clear that the relationships are approximated by quadratic functions, and the strain level in S1-8 is higher than that in S1-0 constantly. In S1-8, it can be seen that the strain at $115 \mathrm{kN} / \mathrm{m}^{2}$ is $8000 \mu$, and the stress calculated from the strain is $30.4 \mathrm{~N} / \mathrm{mm}^{2}$ (elastic modulus of the model liner is $3796 \mathrm{~N} / \mathrm{mm}^{2}$ ). As the tensile strain of PVC pipe described in the Japanese current design for irrigation pipelines [9] is $45 \mathrm{~N} / \mathrm{mm}^{2}$, the strain level of $8000 \mu$ is sufficiently within the elastic region. However, the allowable bending stress which takes account of a safety factor of 3.0 is calculated as $15 \mathrm{~N} / \mathrm{mm}^{2}$, and the stress level of the liner in $\mathrm{S} 1-8$ greatly exceeds the allowable bending stress. Even if the safety is verified by the structural analysis assuming earth pressure distributions by Marston [8] and Spangler [12], the actual stress may exceed the allowable bending stress.

Moreover, it can be assumed that the concentrated strains induce the other risk described as follows. Figure 16 shows the relationships between the pipe deflections and the maximum tensile strains in series 1 . The values in the figure represent the gradients. In all cases, the strains are increasing linearly in proportion to the deflections. With respect to $\mathrm{S} 1-4 \mathrm{i}$, the maximum gradient is approximately $6000 \mu / \%$, and it is more than double in S1-0. It is very sensitive with the increase of the deformation. If the pipe is subjected to shear deformation during earthquake, the risk of pipe failure can be induced.

\section{Conclusions}

In the present study, in order to reveal the mechanical behaviors of liners in damaged host pipes, centrifuge model tests were carried out under various conditions (damage levels of the host pipe, the position of surcharge loading, the ring stiffness of liner, and the soil density). The following conclusions have been obtained.

1. The host pipe which is partially damaged (two cracks) keeps sufficient ring stiffness to resist against the external loads. In the serious damaged state (16 cracks), the influence of the host pipe on the liner is negligible. Therefore, the restraint effect of the deflection of the liner disappears and is not expected when the host pipe is heavily deteriorated. On the other hand, although the host pipe which is 
fully damaged (four cracks and eight cracks) reduces the deflection of the liner, the concentrated strains occurs due to the contact between the edges of the host pipes and the liners.

2. When the ring stiffness of liner increases by five times, the strain localizing at the crown is reduced by $20 \%$. The ring stiffness of pipe should be considered in the design as the important factor in terms of the risk of concentrated strain.

3. When the stiffness of backfill around buried pipes is high $\left(D_{r} 70 \%\right)$, the deformation of the liner greatly decreases in comparison with the case of low stiffness of backfill $\left(D_{r} 20 \%\right)$. However, the degree of the concentrated strain at the crown of the pipe does not decline. It is necessary to consider the effect of the stiffness of the surrounding backfill on the behavior of the liners in trenchless rehabilitation methods.

In terms of practical design, even if the safety is verified by the current structural analysis based on earth pressure distributions by Marston [8] and Spangler [12], the actual stress can be over the allowable bending stress due to the concentrated strain. It can be assumed that the concentrated strain induce a pipe failure especially under a large ground motion during earthquake since the local strains sensitively increase at the points. On that basis, the influence of the concentration of strain should be considered in the design. However, it is difficult to evaluate these risks due to the concentration of strain by the structural analysis since the mechanical behaviors of the liner are affected by the damaged host pipe under significantly complicated mechanism. In the future, a new numerical solution is required to establish the design of the rehabilitated pipeline methods.

Acknowledgments The authors would like to express their grateful thanks to Dr. Liming Li and Mr. Lei Xu, Columbia University in USA for their cooperation in this study. And this work was supported by JSPS Grantin-Aid for Scientific Research (A) No.24248040.

\section{References}

1. Allgood, J.R.: Summary of soil-structure interaction, Naval civil engineering laboratory technical report R771 (1972)

2. EI-Sawy, K., Moore, I.D.: Stability of loosely fitted liners used to rehabilitate rigid pipes. J. Struc. Eng. 124(11), 1350-1357 (1998)

3. Falter, B.: Structural analysis of sewer linings. Trenchless Technol 11(2), 27-41 (1996)

4. Gumbel, J.E., Spasojevic, A.D. and Mair, R.J. : Centrifuge modeling of soil load transfer to flexible sewer liners, New Pipeline Technologies, Security, and Safety, ASCE, 352-362 (2003)

5. Howard, A.K.: Modulus of soil reaction values for buried flexible pipe. J Geotechn Eng Div 103(GT1), 33-43 (1977)

6. Law, T.C.M. and Moore, I.D.: Laboratory investigation on the static response of repaired sewers. Proceedings of the ASCE Pipelines 2002, CDROM (2002)

7. Law, T.C.M. and Moore, I.D.: Numerical modeling of tight fitting flexible liner in damaged sewer under earth loads. Tunnelling and Underground Space Technology 22, 655-665 (2007)

8. Marston, A.: The theory of external loads on closed conduits in the light of the latest experiments, Bulletin 96, Iowa Engineering Experiment Station (1930)

9. Ministry of Agriculture, Forestry and Fisheries of Japan: Design standard for pipeline. (in Japanese) (2009) 
10. Moore, I.D.: Advances in modeling of trenchless pipe installation and repair, Proceedings of the 12th International Conference of International Association for Computer Methods and Advanced in Geomechanics, CDROM (2008)

11. Sawada, Y., Sonoda, Y., Ono, K., Inoue, K., Mohri, Y., Ariyoshi, M., Kawabata, T.: Influences of damage levels of outer aging pipes on mechanical behavior of rehabilitated pipes. IDRE J 291, 25-31 (2014) (in Japanese)

12. Spangler, M.G.: The structural design of flexible pipe culverts, Bulletin 153, Iowa Engineering Experiment Station (1941)

13. Spasojevic, A.D., Mair, R.J., Gumbel, J.E.: Centrifuge modelling of the effects of soil loading on flexible sewer liners. Géotechnique 57(4), 331-341 (2007)

14. Takahashi, Y., Deguchi, T., Li, L., Yamada, K.: A study of the bedding effects of the deteriorated existing pipe on the flexible rehabilitated pipe and its mechanism. J Jpn Sew Works Assoc 39(471), 103-115 (2002)

15. Yoshida, N.: Underground and buried structure, In : Sêco e Pinto, P. (Ed.) Earthquake Geotechnical Engineering, BALKEMA, 987-992 (1999) 